\title{
Effect of PECVD Deposition Parameters on the DLC/PLC Composition of a-C:H Thin Films
}

\author{
Éder C. Oliveira, Sandra A. Cruz* and Paulo H. L. Aguiar \\ Centro de Engenharia, Modelagem e Ciências Sociais Aplicadas, Universidade Federal do ABC, \\ Rua Santa Adélia, 166, 09210-170 Santo André-SP, Brazil
}

\begin{abstract}
Filmes finos de carbono amorfo hidrogenado (a-C:H) têm sido depositados na superfície de materiais para melhorar propriedades mecânicas, ópticas e químicas. Nesse estudo, foi empregado o sistema de deposição química assistida por plasma (PECVD) para sintetizar filmes de a-C:H com fases DLC (tipo diamante) e PLC (tipo polimérico). As pressões parciais de acetileno em argônio foram variadas e as estruturas dos produtos analisadas pela técnica de espectroscopia de reflexãoabsorção no infravermelho (IRRAS) e Raman. Além disso, a morfologia e as espessuras dos filmes foram determinadas por microscopia de força atômica (AFM) e perfilometria, respectivamente.
\end{abstract}

Hydrogenated amorphous carbon $(\mathrm{a}-\mathrm{C}: \mathrm{H})$ thin films were synthesized on the surface of materials to improve mechanical, optical and chemical properties. In the present study, plasma enhanced chemical vapor deposition (PECVD) was performed to produce a-C:H films with PLC (polymer like carbon) and DLC (diamond like carbon) phases. The influences of the acetylene partial pressure and chamber pressure on the chemical structures of the products were evaluated by infrared reflection absorption spectroscopy (IRRAS) and Raman spectroscopy. Moreover, the morphology and thickness of the films were investigated by atomic force microscopy (AFM) and profilometry, respectively.

Keywords: amorphous hydrogenated carbon, PECVD, parameters, diamond like carbon, polymer like carbon

\section{Introduction}

A considerable amount of research has been conducted on hydrogenated amorphous carbon (a-C:H) thin films ${ }^{1,2}$ due to their beneficial effects on the mechanical, optical and chemical properties of materials, particularly for food packaging purposes because of the enhancement of gas barrier properties. ${ }^{1-5}$

In addition, the $\mathrm{a}-\mathrm{C}: \mathrm{H}$ have been studied as a functional barrier to avoid or reduce the migration of possible residual contaminants from recycled polymers. ${ }^{6} \mathrm{a}-\mathrm{C}: \mathrm{H}$ films possess $\mathrm{sp}^{3}{ }^{3}, \mathrm{sp}^{2}$ - and $\mathrm{sp}^{1}$-hybridized carbons, ${ }^{7}$ whose proportion significantly affects their physical and chemical properties. Films with a high percentage of $\mathrm{sp}^{3}$ carbon have properties similar to those of diamonds, such as superior hardness, chemical inertness and high electrical resistance. Alternatively, films with a significant amount of $\mathrm{sp}^{2}$-hybridized carbon are soft like polymers and called PLC (polymer-like carbon). ${ }^{7,8,9}$

*e-mail: sandra.cruz@ufabc.edu.br
The a-C:H films can be synthesized by methods such as ion beam deposition, magnetron sputtering, pulsed laser deposition and plasma enhanced chemical vapor deposition (PECVD). ${ }^{10-13}$ PECVD films are usually prepared with high frequency $(13.56 \mathrm{MHz}$ ) low-temperature plasma from a hydrocarbon precursor gas, typically methane, acetylene, ethylene or benzene. The ions and radicals generated by dissociation/ionization of those gases impinge on the substrates leading to film growth. ${ }^{13-16}$

The physical and chemical properties of a-C:H films deposited by PECVD are dependent on the deposition parameters, including the pressure and gas composition in the plasma chamber. The energy of the ions impinging on the substrate surface also significantly affects the chemical structure of the films that, depending on the processing parameters, can be changed from PLC to DLC phase. ${ }^{11,12,16,17}$

In spite of several studies regarding the a-C:H synthesis by PECVD, ${ }^{11,12,17,18}$ few are the reports on the influence of methane/acetylene partial pressure in argon on the PLC/DLC composition of deposited material. ${ }^{12,19}$ In fact, 
there are still divergences on the influence of the pressure in the chamber on the deposition rate.

Thus, in this work, parameters influencing the structure of a-C:H films, more specifically, the partial pressures of acetylene in argon and the total pressure in the deposition chamber were investigated. The thickness and morphology of the films were determined by profilometry and atomic force microscopy (AFM), respectively, whereas the structure was evaluated by infrared reflection absorption spectroscopy (IRRAS) and Raman spectroscopy.

\section{Experimental}

A Vacutec Plasma PECVD system consisting of a vacuum chamber with two $30 \mathrm{~cm}$ diameter parallel plate electrodes, separated by $4 \mathrm{~cm}$, was employed to deposit the a-C:H films. The system was coupled to a throttle, a power source, a flow meter and a radio frequency (RF) generator $(13.56 \mathrm{MHz})$ as shown in the scheme of Figure 1.

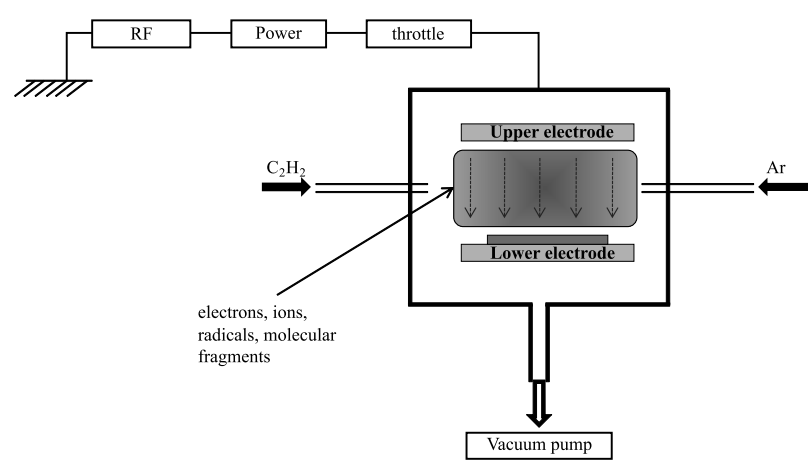

Figure 1. Schematic representation of the PECVD system used for the deposition of a-C:H films.

The plasma power and deposition time were respectively set to $70 \mathrm{~W}^{17,20}$ and $10 \mathrm{~min}$, while the acetylene $(99.8 \%$ purity) to argon (99.9\%) partial pressure and the total pressure in the chamber were varied. Three pressures $(0.5,1.0$ and 1.5 Torr) and six acetylene partial pressures $\left(\phi \mathrm{C}_{2} \mathrm{H}_{2}\right)$ were established by controlling its flow at 25,40 , $50,60,75$ and $95 \mathrm{sccm}$, while the argon gas flow $(\phi \mathrm{Ar})$ was kept constant at $100 \mathrm{sccm}$. In order to facilitate the interpretation and identification throughout the work, the different experimental conditions and the samples were named as shown in Table 1.

All depositions were performed on silicon substrates, which were previously cleaned in an ultrasonic bath with isopropyl alcohol for $3 \mathrm{~min}$, rinsed with deionized water and dried prior use. The a-C:H films were grown on silicon substrates at room temperature, however the temperature increased during the deposition process due to the plasma bombardment. ${ }^{12}$ The thickness of the a-C:H
Table 1. Experimental conditions used to deposit the a-C:H films by PECVD

\begin{tabular}{lccc}
\hline \multicolumn{4}{c}{ Experimental conditions } \\
\hline Sample & $\phi \mathrm{C}_{2} \mathrm{H}_{2} / \mathrm{sccm}$ & $\phi \mathrm{Ar} / \mathrm{sccm}$ & $\mathrm{p} / \mathrm{Torr}$ \\
\hline 1 & 25 & & \\
2 & 40 & & \\
3 & 50 & 100 & \\
4 & 60 & & \\
5 & 75 & & \\
6 & 95 & & \\
\hline 7 & 25 & & \\
8 & 40 & & \\
9 & 50 & & \\
10 & 60 & & \\
11 & 75 & \\
12 & 95 & \\
\hline 13 & 25 & \\
14 & 40 & \\
15 & 50 & \\
16 & 60 & \\
17 & 75 & \\
18 & 95 & \\
\hline
\end{tabular}

films were determined with Dek Tak ${ }^{3}$ Surface Profiler. The surface morphology of the a-C:H films was examined by AFM (Agilent Technologies 5500) operating in contact mode. The images were obtained from the central region of the sample by performing scans on a $10 \times 10$ micrometer area. IRRAS measurements were performed in the 2400 to $3400 \mathrm{~cm}^{-1}$ using a Bomen MB series B102 spectrometer setting the p-polarized light incidence angle to $70^{\circ}$. The structure of the carbonic matrix was characterized using a Jobin Yvon Raman spectrophotometer equipped with a T6400 Scientific Cyntian laser operating at a wavelength of $488 \mathrm{~nm}$ and $8 \mathrm{~mW}$.

\section{Results and Discussion}

\section{Growth rates of the films}

Figure 2 shows how the deposition rate of a-C:H films vary as a function of the acetylene partial pressure and the total pressure in the PECVD chamber.

As shown in Figure 2, a fast increase was observed at the lower partial pressures of acetylene but a saturation behavior was observed at higher partial pressures. This result shows that a larger supply of hydrocarbon in the plasma contributes to film growth. A similar behavior 


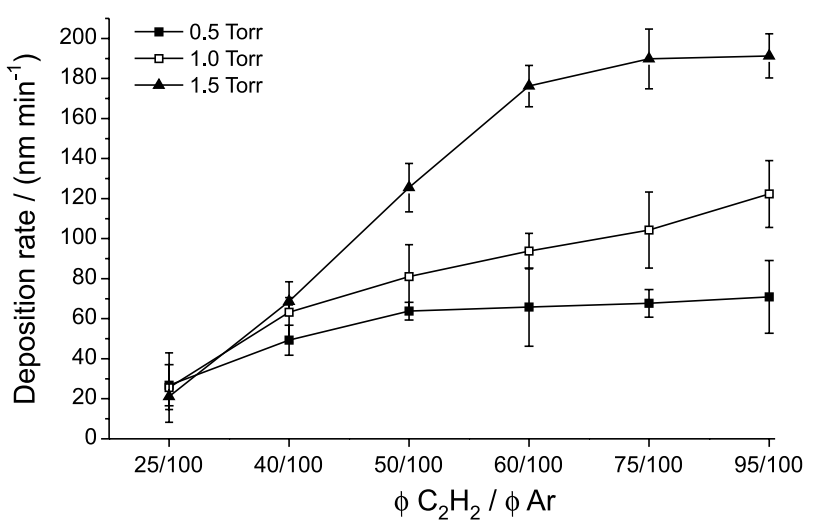

Figure 2. The deposition rate of a-C:H films as a function of the acetylene partial pressure and PECVD chamber pressures of 0.5, 1.0 and 1.5 Torr.

was observed by Gaman et al..$^{11}$ and Cheng et al. ${ }^{18}$ when the partial pressure of methane in argon was increased. Nevertheless, that mechanism cannot explain the saturation behavior observed at higher acetylene partial pressures.

Also, for a given acetylene partial pressure, the deposition rate was enhanced as the chamber pressure was increased since the collisions between ions, radicals, electrons and molecules are more frequent. Thus, the increase of the pressure decreases the mean free path and increases the deposition rate as reported in the literature. . $^{18,19,21}$

However, there are evidences that the deposition rate can decrease as a function of the pressure..$^{12,19,22} \mathrm{In}$ fact, the deposition rate is influenced by the balance between the deposition of hydrocarbon radicals and the etching by $\mathrm{H}^{+}$ bombardment, which is favored at higher pressures, slowing down the a-C:H deposition. This mechanism can adequately explain the saturation behavior of the deposition rate $v s$. acetylene partial pressure plots that are depicted in Figure 2.

\section{IRRAS analysis}

PLC films can present from 40 to $60 \%$ of hydrogen atoms bond to carbon atoms with $\mathrm{sp}^{1}$ and $\mathrm{sp}^{2}$ hybridization. ${ }^{11,12,16,17,20}$ Also, the vibration modes of the $\mathrm{CH}$ bonds characteristic of these films are found in the $2800-3000 \mathrm{~cm}^{-1}$ range. Thus, IRRAS can provide valuable information about type of $\mathrm{CH}$ bonds present in the films, as shown in Figure 3.

The results shown in Figure 3 revealed bands at 2975, 2920 and $2885 \mathrm{~cm}^{-1}$, range can be attributed to symmetric vibrations of $\mathrm{sp}^{2}-\mathrm{CH}_{2}$ groups, asymmetric $\mathrm{sp}^{3}$ or $\mathrm{sp}^{3}-\mathrm{CH}_{2}-\mathrm{CH}$ and symmetric $\mathrm{sp}^{3}$ or $\mathrm{sp}^{3}-\mathrm{CH}_{3}-\mathrm{CH}_{2}$ vibrations. Overall, these bands are characteristic of PLC structures and consistent with those reported in the literature. ${ }^{9,11,12,23,24}$ In fact, better defined C-H bands were observed for the samples prepared at higher acetylene
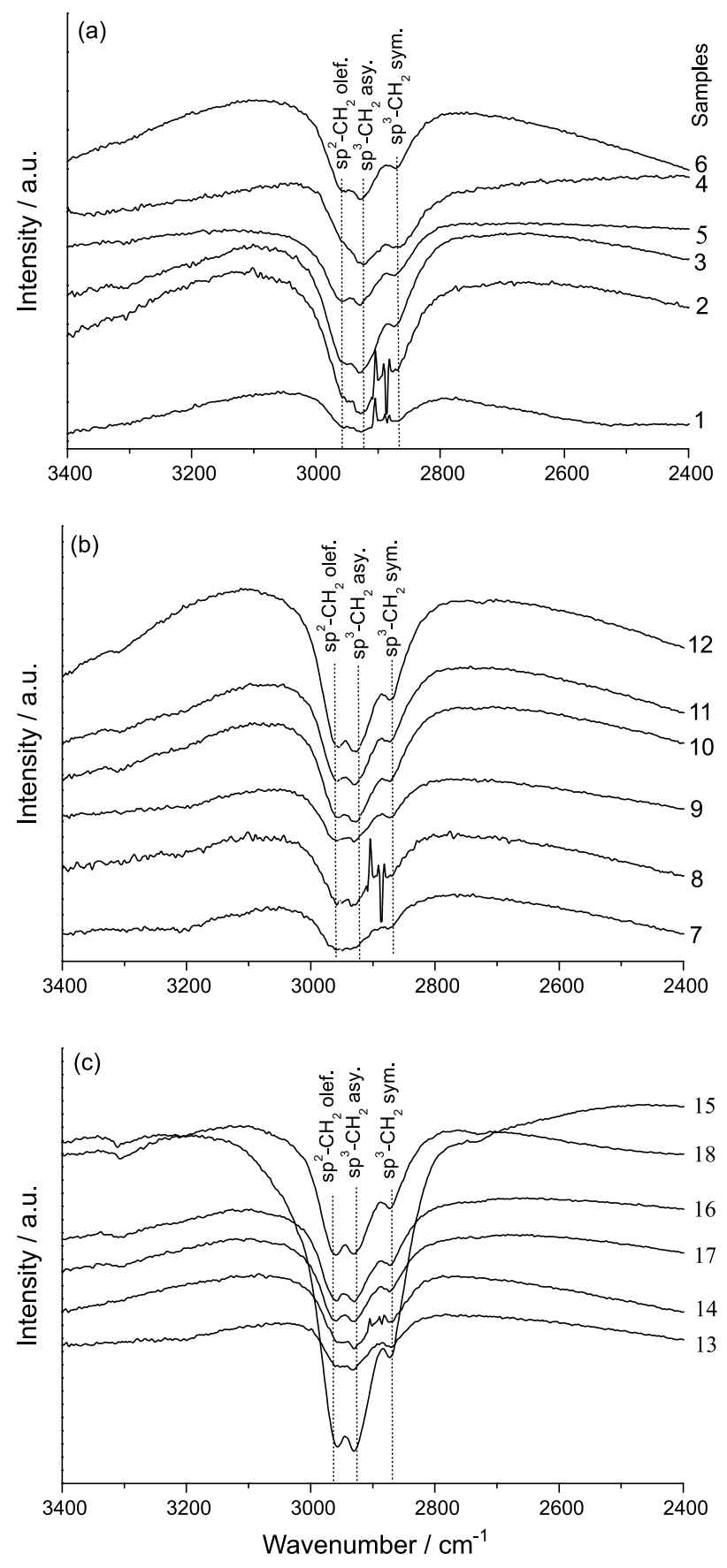

Figure 3. IRRAS spectra of samples deposited at (a) 0.5 , (b) 1.0 and (c) 1.5 Torr. The spectra show the typical vibration modes for $\mathrm{CH}$ bonds at $2800-3000 \mathrm{~cm}^{-1}$.

partial pressure and higher PECVD chamber pressure. As observed in other studies, ${ }^{12}$ the a-C:H film structure can change from DLC to PLC as the total pressure is increased even at the same partial pressure of methane and argon.

According to the literature, ${ }^{18}$ the dissociation of $\mathrm{C}_{2} \mathrm{H}_{2}$ by $\mathrm{Ar}$ ions and electrons generates mainly ethinyl radical $\left(\mathrm{C}_{2} \mathrm{H}\right)$ and hydrogen atoms according to the reaction: 
$\mathrm{Ar}^{*}+\mathrm{C}_{2} \mathrm{H}_{2} \rightarrow \mathrm{Ar}+\mathrm{C}_{2} \mathrm{H}_{2}^{+}$

$\mathrm{C}_{2} \mathrm{H}_{2}^{+}+\mathrm{e}^{-} \rightarrow \mathrm{C}_{2} \mathrm{H}+\mathrm{H}$

The probability of effective collision and formation of hydrogen atoms is higher at higher pressures, favoring the formation of PLC films.

\section{Raman analysis}

The Raman spectra of a-C:H films deposited by PECVD are depicted in Figures 4.

The spectra were analyzed by Gaussian deconvolution, and the bands found at 1480 ( $\mathrm{G}$ band) and $1200 \mathrm{~cm}^{-1}$ (D band) are characteristic of DLC films. ${ }^{9}$

The decrease in the ratio of the $\mathrm{D}$ and $\mathrm{G}$ band intensities (ID/IG ratio) and the shift in their position to lower wavelengths are indicatives of less extended graphitic domains, which were attributed to an increase in the degree of disorder of the $\mathrm{sp}^{2}$ bonds and an increase in the number of $\mathrm{sp}^{3}$ bonds in the structure. Thus, the characteristics of DLC films become increasingly pronounced. ${ }^{9,25}$ The ID/IG ratio and the positions of the $\mathrm{G}$ and $\mathrm{D}$ bands of the samples are presented in Table 2 .

To determine which deposition parameters led to the formation of DLC films, those with the lowest ID/IG ratio were evaluated. In particular, samples 5 and 9 presented an ID/IG ratio of 0.13 (Table 2) and the $\mathrm{G}$ and D bands at the lowest wavelengths. The results indicated that sample 5 was the most structurally similar to DLC films. The effect of pressure and acetylene partial pressure on the structural characteristics of a-C:H films can be attributed to the impact energy of the ionic species generated in plasma..$^{9,10,19,24}$ It is established that the energy of incident ions decreases as the pressure increases and the mean free path decreases. ${ }^{19}$

According to literature, ${ }^{9}$ ions with sufficient energy to reach the surface of a-C:H films are inserted following the subplantation model. According to this model, the density of DLC films increases when the incident carbon ions $\left(\mathrm{C}^{+}\right)$penetrate the first atomic layer of the film, forming a $\mathrm{sp}^{3}$-hybridized carbon. Alternatively, low energy carbon ions lay on the surface of the film, forming $\mathrm{sp}^{2}$-hybridized carbons.

According to the Raman results (Figure 4), the flux has little effect on the formation of DLC films, and sensitive variations in the ID/IG values were observed at deposition pressures of 0.5 and 1.0 Torr. However, the ID/IG ratio of most samples deposited at 1.5 Torr increased, indicating that a transition in DLC to PLC films had occurred.

Generally, the increase in pressure as well as acetylene partial pressure should result in high rates of dissociation and ionization promoting the hydrogenation of a-C:H films and
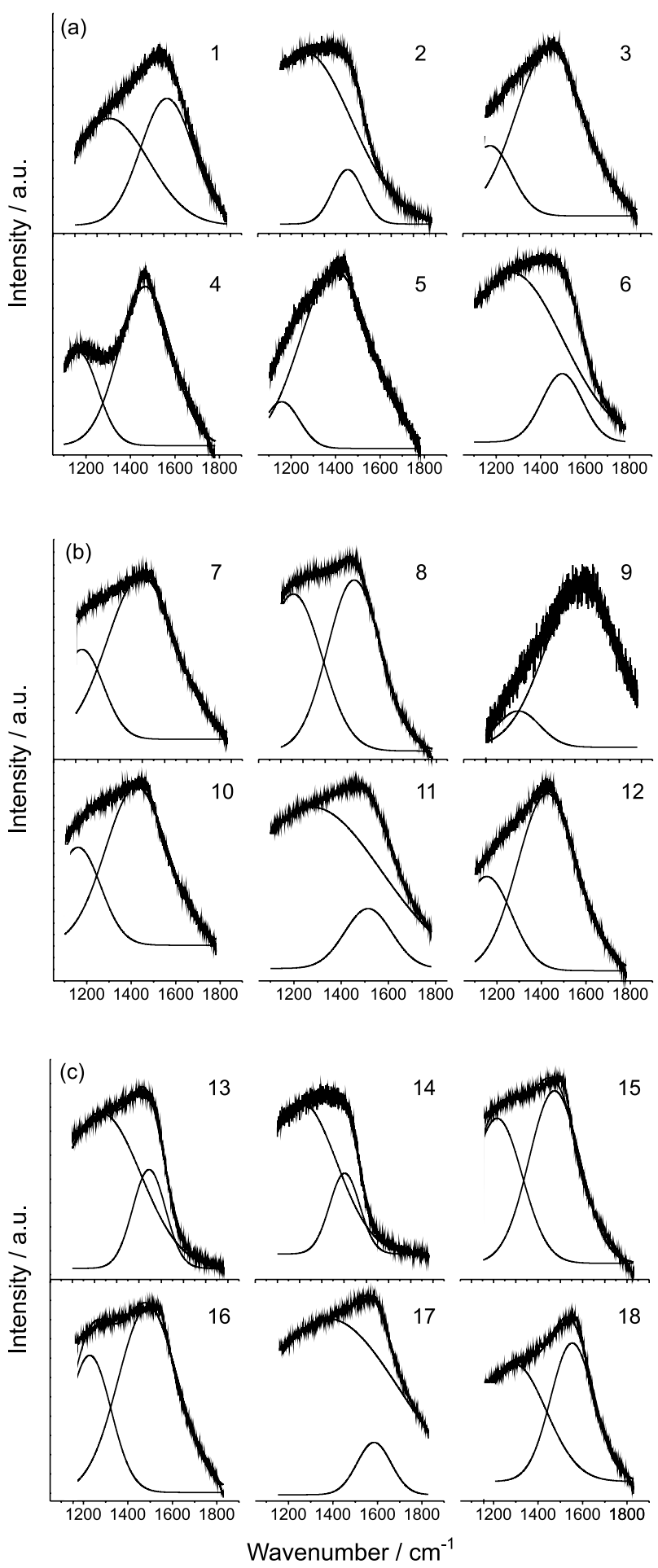

Figure 4. Raman spectra of a-C:H films deposited by PECVD on silicon substrates at (a) 0.5 (1-6), (b) 1.0 (7-12) and (c) 1.5 Torr (13-18).

increasing PLC characteristics. In contrast, the lower energy of the incident ions at 1.5 Torr and the effect of subplantation should favor the growth of carbon films with higher $\mathrm{sp}^{1}$ and $\mathrm{sp}^{2}$ hybridization. ${ }^{9}$

However, the Raman studies indicated that this second process is more important in our conditions since the 
(a)

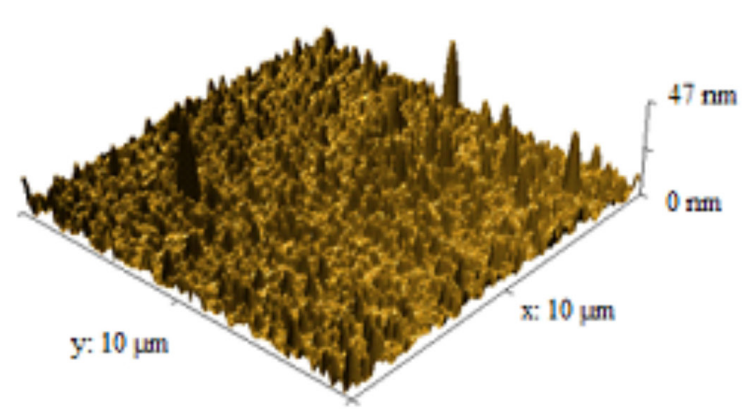

DLC

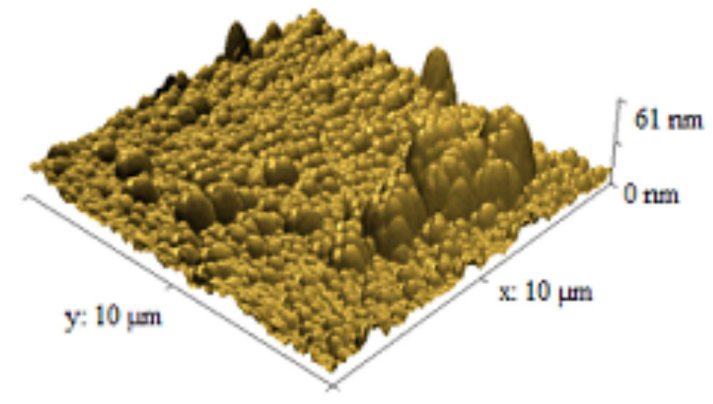

PLC

Figure 5. Typical 3D AFM images of DLC (a) and PLC (b) a-C:H films deposited by PECVD on silicon.

Table 2. Positions and intensities of Raman spectral bands of a-C:H films deposited by PECVD

\begin{tabular}{lccc}
\hline Sample & $\mathrm{G}$ band $/ \mathrm{cm}^{-1}$ & $\mathrm{D}$ band $/ \mathrm{cm}^{-1}$ & $\mathrm{ID} / \mathrm{IG}$ \\
\hline 1 & 1515 & 1264 & 1.24 \\
2 & 1603 & 1294 & 1.32 \\
3 & 1390 & 1122 & 0.26 \\
4 & 1467 & 1163 & 0,45 \\
5 & 1398 & 1157 & 0.13 \\
6 & 1603 & 1295 & 1.32 \\
7 & 1395 & 1128 & 0.34 \\
8 & 1430 & 1156 & 0.98 \\
9 & 1531 & 1245 & 0.13 \\
10 & 1423 & 1160 & 0.44 \\
11 & 1490 & 1228 & 0.52 \\
12 & 1426 & 1154 & 0.44 \\
13 & 1445 & 1228 & 0.26 \\
14 & 1425 & 1153 & 0.64 \\
15 & 1500 & 1314 & 15.96 \\
16 & 1514 & 1275 & 7.94 \\
17 & 1584 & 1380 & 13.89 \\
18 & 1560 & 1377 & 11.15 \\
\hline
\end{tabular}

formation of a-C:H films with lower ID/IG ratio was observed at lower pressures, indicating the formation of less hydrogenated materials (DLC). Thus, the subplantation process should be predominant even at 0.5 Torr as a consequence of the higher impact energy of the species present in the plasma.

\section{Morphology of a-C:H films}

Figure 5 shows AFM images of DLC (sample 5) and PLC a-C:H films deposited on silicon (sample 15).

An irregular morphology, including rounded grains with different sizes and nucleation shapes, was present on the surface of the PLC films (sample 15, Figure 5b). On the other hand, DLC films (sample 5, Figure 5a) presented sharper and more structured surface as expected for the formation of needle like micro-structures. Thus, the PLC and DLC phases showed different surface morphologies due to variations in the deposition parameters.

\section{Conclusions}

In the present study, a-C:H films were synthesized by PECVD varying deposition parameters such as the pressure and concentration of acetylene in argon. The profilometry results revealed that the film thickness increased as a function of acetylene pressure as expected for a higher concentration of chemical species in the plasma. At a constant partial pressure of acetylene in argon, an increase in the operating pressure led to the formation of thicker films due to an increase in the number of effective collisions, consequence of the shorter mean free path. The IRRAS and Raman spectroscopy revealed that PLC structures were favored at low acetylene partial pressure and high chamber pressure (sample 15), whereas the formation of DLC films was favored at high acetylene partial pressure and low PECVD chamber pressure (sample 5). Moreover, AFM analysis revealed that materials with different morphologies could be generated by varying the deposition parameters.

\section{Acknowledgments}

The authors would like to acknowledge the Brazilian Synchrotron Light Laboratory (LNLS), UFABC and Coordenação de Aperfeiçoamento de Pessoal de Nível Superior (CAPES).

\section{References}

1. Goswami, R.; Jana, S. T.; Ray, S.; J. Phys. D: Appl. Phys. 2008, $41,155413$. 
2. Vasquez, B. S.; Jacob, W. C.; Achete, A.; Diamond Relat. Mater. 2000, 9, 1971.

3. Kodama, H.; Shirakura, A.; Hotta, A.; Suzuki, T.; Surf. Coat. Technol. 2006, 201, 913.

4. Abbas, G.; McLaughlin, J.; Harkin-Jones, E.; Diamond Relat. Mater. 2004, 13, 1342.

5. Li, J.; Gong, C.; Tian, X.; Yang, S.; Fu, R. K. Y.; Chu, P. K.; Appl. Surf. Sci. 2009, 255, 3983.

6. Cruz, S. A.; Zanin, M.; Nerín, C.; de Moraes, M. A. B.; Food Addit. Contam. 2006, 23, 100.

7. Staryga, E.; Bak, G. W.; Diamond Relat. Mater. 2005, 14, 23.

8. Sullivan, J. L.; Saied,S.O.; Zaharia, T.; Acta Phys. Pol., A 2010, $120,156$.

9. Robertson, J.; Mater. Sci. Eng., R 2002, 37, 129.

10. Maheswaran, R.; Shivaraman, R.; Thiruvadigal, D.; J. Non-Cryst. Solids 2011, 357, 1710.

11. Gaman, S.; Morosanu, C.; Dumitrache, F.; Apetroaei, N.; Yastrebov, S.; J. Optoelectron. Adv. Mater. 2007, 9, 1450.

12. Stan, G. E.; Marcov, D. A.; Popa. A. C.; Husanu, M. A.; Dig. J. Nanomater. Biostruct. 2010, 5, 705.

13. Keudell, A.; Thin Solid Films 2002, 402, 1.

14. Chan, C. M.; Ko, T. M.; Hiraoka, H.; Surf. Sci. Rep. 1996, $24,1$.

15. Bogaerts, A.; Neyts, E.; Gijbels, R.; Mullen, V. D. J.; Spectrochim. Acta, Part B 2002, 57, 609.
16. Piazza, F.; Morell, G.; Diamond Relat. Mater. 2009, 18, 43.

17. Ristein, J.; Stief, R. T.; Ley, L.; J. Appl. Phys. 1998, 84, 3836.

18. Cheng, Y. H.; Wu, Y. P.; Chen, J. G.; Qiao, X. L.; Xie, C. S.; Tay, B. K.;Lau, S. P.; Shi, X. Surf. Coat. Technol. 2000, 135, 27.

19. Ryu, H. J.; Kim, S. H.; Hong, S. H.; Mater. Sci. Eng., A 2000 , 277, 57.

20. Marins, N. M. S.; Mota, R. P.; Honda, R. Y.; Nascente, P. A. P.; Kayama, M. E.; Kostov, K. G.; Algatti, M. A. Cruz, N. C.; Rangel, E. C.; Surf. Coat. Technol. 2011, 206, 640.

21. Benmassaoud, A. A.; Paynter, R. W.; Thin Solid Films 1996, 287, 125.

22. Deng, X.R.; Leng, Y.X.; Dong, X.; Sun, H.; Huang, N.; Surf. Coat. Technol. 2011, 206, 1007.

23. Fedosenko, G.; Korzec, D.; Schwabedissen, A.; Engemann, J.; Braca, E.; Kenny, J. M. Diamond Relat. Mater. 2001, 10, 920.

24. Boutroy, N.; Yann, P.; Rius, J. M.; Florence, A.; Von B. H. J.; Cantin, J .L.; Abel, F.; Andreas, Z.; Casiraghi, C.; Ferrari, A. C.; Robertson, J.; Diamond Relat. Mater. 2006, 15, 921.

25. Tuinstra, F.; Koenig, J. L.; J. Chem. Phys. 1970, 53, 3.

Submitted: October 24, 2011

Published online: August 24, 2012

FAPESP has sponsored the publication of this article. 